Check for updates

Cite this: Chem. Sci., 2019, 10, 587

๑ All publication charges for this article have been paid for by the Royal Society of Chemistry

Received 21st September 2018 Accepted 20th October 2018

DOI: $10.1039 / \mathrm{c} 8 \mathrm{sc} 04204 \mathrm{~g}$

rsc.li/chemical-science

\section{Mobility of hydrated alkali metal ions in metallosupramolecular ionic crystals $\uparrow$}

\author{
Nobuto Yoshinari, (D) Satoshi Yamashita, Yosuke Fukuda, (D) Yasuhiro Nakazawa \\ and Takumi Konno (D) *
}

The design and creation of ionic crystals that show high mobility of ionic species in the solid state has long been a research topic of considerable attention not only due to the practical applications of these materials but also due to the correlation of such ionic species with ion-transport biological systems. In this work, we report the mobility of alkali metal ions $\left(\mathrm{M}=\mathrm{Li}^{+}, \mathrm{Na}^{+}, \mathrm{K}^{+}\right)$in the ionic crystals $\mathrm{M}_{6}\left[\mathrm{Rh}_{4} \mathrm{Zn}_{4} \mathrm{O}(\mathrm{L} \text {-cysteinate })_{12}\right]$. $n \mathrm{H}_{2} \mathrm{O}\left(\mathrm{M}_{6}[1] \cdot n \mathrm{H}_{2} \mathrm{O}\right)$. In $\mathrm{M}_{6}[1] \cdot n \mathrm{H}_{2} \mathrm{O}$, alkali metal ions are distributed in a disordered manner, together with a number of water molecules, within a rigid hydrogen-bonded framework of anionic clusters of [1] ${ }^{6-}$. The alternating current conductivities of $\mathrm{M}_{6}[1] \cdot n \mathrm{H}_{2} \mathrm{O}$ in the solid state increase in the order of $\mathrm{Li}_{6}[1] \cdot n \mathrm{H}_{2} \mathrm{O}<$ $\mathrm{Na}_{6}[1] \cdot n \mathrm{H}_{2} \mathrm{O}<\mathrm{K}_{6}[1] \cdot n \mathrm{H}_{2} \mathrm{O}$, which is opposite to the order of the naked ionic radii. The conductivities reach the superionic level of $\sigma=1.3 \times 10^{-2} \mathrm{~S} \mathrm{~cm}^{-1}$ at $300 \mathrm{~K}$ for a single crystal of $\mathrm{K}_{6}[1] \cdot n \mathrm{H}_{2} \mathrm{O}$. These results reflect the high mobility of hydrated alkali metal ions in the crystal lattice of $\mathrm{M}_{6}[1] \cdot n \mathrm{H}_{2} \mathrm{O}$, which is supported by solid-state NMR spectroscopy, together with ion diffusion experiments in the solid state. The high mobility leads to quick exchange of $\mathrm{K}^{+}$ions in $\mathrm{K}_{6}[1] \cdot n \mathrm{H}_{2} \mathrm{O}$ with $\mathrm{Li}^{+}$and $\mathrm{Na}^{+}$ions with retention of single crystallinity.

\section{Introduction}

Ionic solids consisting of cationic and anionic species are one of the most basic substances in nature. A fundamental concept of natural ionic solids is the tight binding of ionic species in crystal lattices due to coulombic interactions between cations and anions. ${ }^{1}$ Thus, ionic species in natural ionic solids rarely migrate in the solid state. In 1914, Tubandt et al. found that AgI forms a solid phase ( $\alpha$-AgI) that shows a high conductivity over a range of high temperatures $\left(147\right.$ to $\left.555{ }^{\circ} \mathrm{C}\right) .{ }^{2}$ Since this pioneering discovery, the conducting behavior of ionic species in the solid state has been extensively investigated in connection with a wide variety of practical applications for these materials as batteries, ${ }^{3}$ fuel cells, ${ }^{4}$ sensors,${ }^{5}$ and thermoelectric elements. ${ }^{6}$ In particular, lithium-ion conductors have attracted much attention because of their potential utility as electrolytes for lithium-ion secondary batteries. ${ }^{7}$ However, global lithium consumption, and therefore, the price of lithium carbonate, has been rapidly increasing, and the high energy density of lithium-

Department of Chemistry, Graduate School of Science, Osaka University, Toyonaka, Osaka 560-0043, Japan.E-mail: konno@chem.sci.osaka-u.ac.jp

$\dagger$ Electronic supplementary information (ESI) available: Experimental in detail, solution NMR (Fig. S1 and S2), IR (Fig. S3 and S20), diffuse reflection (Fig. S4 and S21), CD (Fig. S5 and S22), PXRD (Fig. S6 and S7), crystal structure (Fig. S8-S12 and Table S9), photographs (Fig. S13 and S19), ac conductivity (Fig. S14 and Tables S1-S4), solid NMR (Fig. S15-S18, S23 and Tables S5-S8), TG/DTA (Fig. S24-S26). CCDC 1536857-1536859. For ESI and crystallographic data in CIF or other electronic format see DOI: $10.1039 / \mathrm{c} 8 \mathrm{sc} 04204 \mathrm{~g}$ ion batteries is an inherent safety risk. This has stimulated recent research into other naturally abundant, less expensive elements, such as sodium and potassium. ${ }^{8}$

In general, the larger $\mathrm{Na}^{+}$and $\mathrm{K}^{+}$ions are more strongly trapped in crystal lattices than smaller ions, such as $\mathrm{Li}^{+}$and $\mathrm{H}^{+} .9$ To allow larger alkali metal ions to move within an ionic solid, it is necessary to increase the density of cations in the material while minimizing their coulombic interactions with lattice counter-anions. The use of large metal-organic clusters with high negative charges as the anionic component in such materials meets these requirements because (i) enlargement of the anions reduces their surface charge density, (ii) the high negative charge of an anionic cluster requires many alkali metal ions to be present for charge balance, (iii) packing arrangements of large cluster anions can afford large inter-cluster spaces that are available as effective conducting pathways for carrier cations, and (iv) a variety of soluble ionic solids can be easily and reproducibly created under ambient conditions in combination with different alkali metal ions. The introduction of solvent molecules into an ionic lattice can also contribute to reducing coulombic interactions between carrier cations and host anions due to the electrostatic shielding effect of solvent molecules.

With this in mind, we now report the ion-conducting features of a series of ionic solids, $\mathrm{M}_{6}\left[\mathrm{Rh}_{4} \mathrm{Zn}_{4} \mathrm{O}(\mathrm{L}-\mathrm{cys})_{12}\right] \cdot n \mathrm{H}_{2} \mathrm{O}$ $\left(\mathrm{M}_{6}[\mathbf{1}] \cdot n \mathrm{H}_{2} \mathrm{O}\right)\left(\mathrm{M}=\mathrm{Li}^{+}, \mathrm{Na}^{+}\right.$and $\mathrm{K}^{+} ; \mathrm{L}-\mathrm{H}_{2} \mathrm{cys}=\mathrm{L}$-cysteine $)$, whose $\mathrm{K}^{+}$salt has been previously synthesized by us. ${ }^{\mathbf{1 0 , 1 1}}$ These ionic solids are composed of cluster anions $\left[\mathrm{Rh}_{4} \mathrm{Zn}_{4} \mathrm{O}(\mathrm{L}-\mathrm{cys})_{12}\right]^{6-}$ 
$\left([1]^{6-}\right)$ and alkali metal ions in a $1: 6$ ratio, together with a number of water molecules of crystallization, and are easily crystallized from water at room temperature. We found that the alternating current (AC) conductivity of $\mathrm{M}_{6}[\mathbf{1}] \cdot n \mathrm{H}_{2} \mathrm{O}$ increases in the order of $\mathrm{M}=\mathrm{Li}^{+}<\mathrm{Na}^{+}<\mathrm{K}^{+}$, which is the reverse of the usual order for solid-state ion-conducting materials. Remarkably, single-crystal $\mathrm{K}_{6}[\mathbf{1}] \cdot n \mathrm{H}_{2} \mathrm{O}$ exhibited a particularly high ion conductivity due to the fast migration of hydrated $\mathrm{K}^{+}$ions in the crystal lattice. Such a superionic conductivity of hydrated $\mathrm{K}^{+}$ ions in the solid state is unprecedented.

\section{Results and discussion}

\section{Synthesis and crystal structures}

The potassium salt of $\left[\mathrm{Rh}_{4} \mathrm{Zn}_{4} \mathrm{O}(\mathrm{L}-\mathrm{cys})_{12}\right]^{6-}\left([1]^{6-}\right)$ was prepared according to a previously reported procedure ${ }^{\mathbf{1 0}}$ and purified by recrystallization from an aqueous $\mathrm{KCl}$ solution. The new lithium and sodium salts of $[\mathbf{1}]^{6-}, \mathrm{Li}_{6}[\mathbf{1}] \cdot n \mathrm{H}_{2} \mathrm{O}$ and $\mathrm{Na}_{6}[\mathbf{1}]$. $n \mathrm{H}_{2} \mathrm{O}$, were obtained by cation exchange via the protonated species $\left(\mathrm{H}_{6}\left[\mathrm{Rh}_{4} \mathrm{Zn}_{4} \mathrm{O}(\mathrm{L}-\mathrm{cys})_{12}\right] \cdot 15 \mathrm{H}_{2} \mathrm{O}\right) \cdot \uparrow$ Successful exchange was demonstrated by the ${ }^{7} \mathrm{Li}$ and ${ }^{23} \mathrm{Na}$ NMR spectra of the purified salts dissolved in $\mathrm{D}_{2} \mathrm{O}$ (Fig. $\mathrm{S} 1$ and $\mathrm{S} 2 \dagger$ ), as well as the atomic absorption spectral analysis of $\mathrm{Li}$ and $\mathrm{Na}$ atoms in the samples. The retention of the cluster structure of $[\mathbf{1}]^{6-}$ in $\mathrm{Li}_{6}[\mathbf{1}]$. $n \mathrm{H}_{2} \mathrm{O}$ and $\mathrm{Na}_{6}[\mathbf{1}] \cdot n \mathrm{H}_{2} \mathrm{O}$ was confirmed by their diffuse reflectance, circular dichroism (CD) and IR spectra, which are essentially the same as those of $\mathrm{K}_{6}[\mathbf{1}] \cdot n \mathrm{H}_{2} \mathrm{O}$ (Fig. S3-S5†). The phase purity of each polycrystalline sample of $\mathrm{M}_{6}[\mathbf{1}] \cdot n \mathrm{H}_{2} \mathrm{O}$ was confirmed by powder X-ray diffraction (PXRD) data, which matched well with the pattern simulated from the single-crystal structures (Fig. S6 and S7 $\dagger$ ).

The crystal structure of $\mathrm{K}_{6}[\mathbf{1}] \cdot n \mathrm{H}_{2} \mathrm{O}$ was previously investigated using a laboratory X-ray source at $200 \mathrm{~K} .{ }^{11}$ However, the limited data quality from this analysis prevented resolution of the $\mathrm{K}^{+}$positions in the lattice. In the current work, the crystal data of $\mathrm{Li}_{6}[\mathbf{1}] \cdot n \mathrm{H}_{2} \mathrm{O}, \mathrm{Na}_{6}[\mathbf{1}] \cdot n \mathrm{H}_{2} \mathrm{O}$ and $\mathrm{K}_{6}[\mathbf{1}] \cdot n \mathrm{H}_{2} \mathrm{O}$ were evaluated using synchrotron $\mathrm{X}$-ray radiation at $100 \mathrm{~K}$, which indicated that $\mathrm{Li}_{6}[\mathbf{1}] \cdot n \mathrm{H}_{2} \mathrm{O}, \mathrm{Na}_{6}[\mathbf{1}] \cdot n \mathrm{H}_{2} \mathrm{O}$ and $\mathrm{K}_{6}[\mathbf{1}] \cdot n \mathrm{H}_{2} \mathrm{O}$ crystals are isomorphs. The crystals contain hexaanionic clusters of $\left[\mathrm{Rh}_{4} \mathrm{Zn}_{4} \mathrm{O}(\mathrm{L} \text {-cys })_{12}\right]^{6-}$, each bearing 12 noncoordinating carboxylate $\left(\mathrm{COO}^{-}\right)$and 12 metal-bound amino $\left(\mathrm{NH}_{2}\right)$ functional groups from the L-cys ligands (Fig. 1a and $\mathrm{S} 8 \dagger$ ). These functional groups form multiple inter-cluster $\mathrm{NH} \cdots \mathrm{O}$ hydrogen bonds to afford a rigid 3D supramolecular lattice with an lcy topology (Fig. 1b, S9 and S10†). ${ }^{11}$ The framework has a 3D network of open channels, which can serve as conduction pathways for alkali metal cations (Fig. 1c). The narrowest section of the channel is a slit-like window surrounded by carboxylate groups from five different cluster anions, with approximate dimensions of $5 \AA \times 11 \AA$ (Fig. S11†).

The positions of all six $\mathrm{K}^{+}$ions per cluster anion in $\mathrm{K}_{6}[\mathbf{1}]$. $n \mathrm{H}_{2} \mathrm{O}$ were determined by this analysis, although four of them were disordered with water molecules even at $100 \mathrm{~K}$. In contrast, only one disordered $\mathrm{Na}^{+}$ion site was found in $\mathrm{Na}_{6}[\mathbf{1}] \cdot n \mathrm{H}_{2} \mathrm{O}$, and no $\mathrm{Li}^{+}$ions could be found in $\mathrm{Li}_{6}[\mathbf{1}] \cdot n \mathrm{H}_{2} \mathrm{O}$. This is presumably due to the severe disorder of the $\mathrm{Na}^{+}$and $\mathrm{Li}^{+}$ions and their low electron density compared with that of $\mathrm{K}^{+}$. All $\mathrm{K}^{+}$ions in $\mathrm{K}_{6}[\mathbf{1}]$.

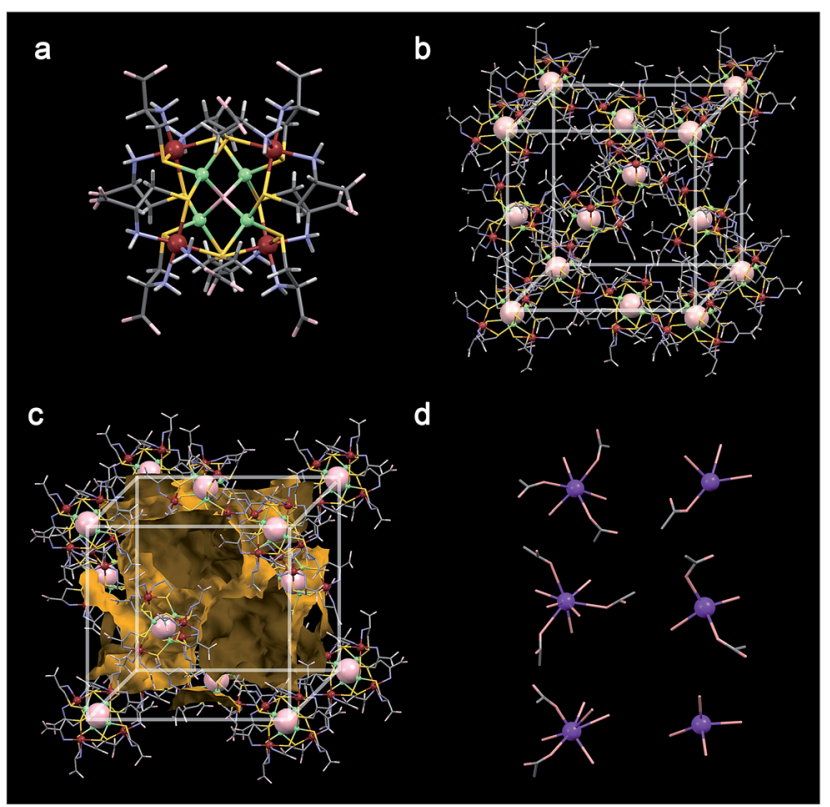

Fig. 1 Perspective views of the molecular structure of $\left[\mathrm{Rh}_{4} Z \mathrm{Zn}_{4} \mathrm{O}(\mathrm{L}-\right.$ cys) $\left.{ }_{12}\right]^{6-}(a)$, the packing structure of $\left[\mathrm{Rh}_{4} \mathrm{Zn}_{4}(\mathrm{~L}-\mathrm{cys})_{12} \mathrm{O}\right]^{6-}$ anions (b), the packing structure showing void space (orange surface, (c)), and six different coordination environments of potassium ions (d) in $K_{6}[1]$. $n \mathrm{H}_{2} \mathrm{O}$. The central oxygen atoms in (b) and (c) are represented by a space-filling model. Color code: Rh, brown; Zn, green; S, yellow; K, purple; O, pink; N, blue; C, gray; $\mathrm{H}$, white.

$n \mathrm{H}_{2} \mathrm{O}$ exist as hydrated ions and are coordinated by several water molecules (Fig. 1d and $\mathrm{S} 12 \dagger$ ). Five of the $\mathrm{K}^{+}$ions are also coordinated by carboxylate group(s) from the anion framework, while the sixth is surrounded only by water molecules. A total of 55 water molecules were found in the X-ray structure of $K_{6}[1]$. $n \mathrm{H}_{2} \mathrm{O} ; 28$ water molecules coordinate to the $\mathrm{K}^{+}$ions, and the

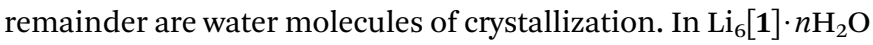
and $\mathrm{Na}_{6}[\mathbf{1}] \cdot n \mathrm{H}_{2} \mathrm{O}$, a total of 77.5 and 66 water molecules were found in the Fourier maps.

\section{Alternating current conductivities}

The open anion framework structure, the disordered distribution of alkali metal ions through the large open channels in that framework, and their high lattice water content prompted us to investigate the mobility of the alkali metal ions in $\mathrm{M}_{6}[\mathbf{1}] \cdot n \mathrm{H}_{2} \mathrm{O}$. Freshly prepared, high-quality single crystals of $\mathrm{Li}_{6}[\mathbf{1}] \cdot n \mathrm{H}_{2} \mathrm{O}$, $\mathrm{Na}_{6}[\mathbf{1}] \cdot n \mathrm{H}_{2} \mathrm{O}$ and $\mathrm{K}_{6}[\mathbf{1}] \cdot n \mathrm{H}_{2} \mathrm{O}$ were selected, and their AC conductivities were measured using carbon-paste electrodes connected to gold wires (Fig. S13 $\dagger$ ). ${ }^{12}$ At $300 \mathrm{~K}$, the Nyquist plot of $\mathrm{Li}_{6}[\mathbf{1}] \cdot n \mathrm{H}_{2} \mathrm{O}$ showed a single semi-circular shape with a tail (Fig. 2a), which is expected if the motion of the carrier ions through the crystal is blocked at the interface of the gold electrode. By applying an equivalent circuit (a parallel RC circuit) to the single semicircle in the impedance data, the conductivity value $\sigma$ was estimated to be $1.9 \times 10^{-6} \mathrm{~S} \mathrm{~cm}^{-1}$. By contrast, the plots of $\mathrm{K}_{6}[\mathbf{1}] \cdot n \mathrm{H}_{2} \mathrm{O}$ and $\mathrm{Na}_{6}[\mathbf{1}] \cdot n \mathrm{H}_{2} \mathrm{O}$ showed only tails without semi-circles when the highest measurement frequency was set to the device limit of $10 \mathrm{MHz}$ (Fig. 2b, c, and S14 $\dagger$ ), which is due 
a
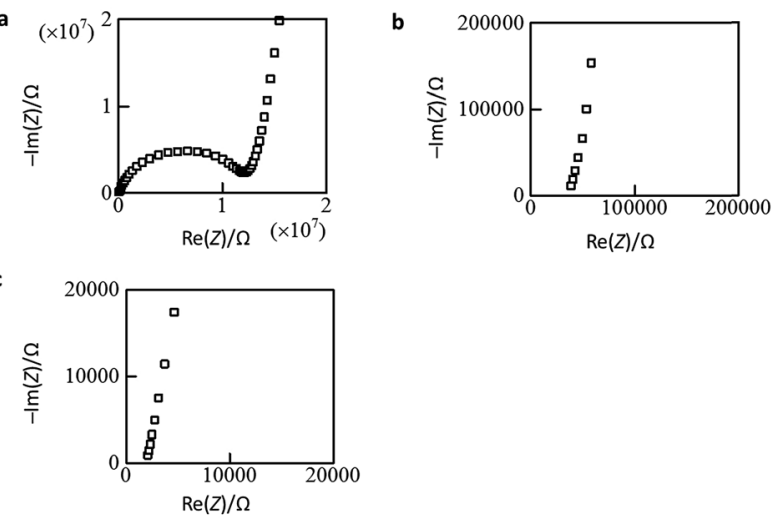

Fig. 2 Nyquist plots of single-crystal samples. (a) $\mathrm{Li}_{6}[1] \cdot n \mathrm{H}_{2} \mathrm{O}$, (b) $\mathrm{Na}_{6}[1] \cdot n \mathrm{H}_{2} \mathrm{O}$, and (c) $\mathrm{K}_{6}[1] \cdot n \mathrm{H}_{2} \mathrm{O}$.

to a higher shift of the cut-off frequency $\left(f_{\mathrm{c}}=1 / 2 \pi \mathrm{RC}\right)$ for the RC circuit with a lower resistance. From the $x$ intercepts of the linear tails in the Nyquist plots, the conductivity values at $300 \mathrm{~K}$ were determined to $5.0 \times 10^{-4} \mathrm{~S} \mathrm{~cm}^{-1}$ for $\mathrm{Na}_{6}[1] \cdot n \mathrm{H}_{2} \mathrm{O}$ and 1.3 $\times 10^{-2} \mathrm{~S} \mathrm{~cm}^{-1}$ for $\mathrm{K}_{6}[\mathbf{1}] \cdot n \mathrm{H}_{2} \mathrm{O}$. Thus, the conductivities of $\mathbf{M}_{6}[\mathbf{1}] \cdot n \mathrm{H}_{2} \mathrm{O}$ are highly dependent on the cations present, increasing in the order of $\mathrm{Li}_{6}[\mathbf{1}] \cdot n \mathrm{H}_{2} \mathrm{O}<\mathrm{Na}_{6}[\mathbf{1}] \cdot n \mathrm{H}_{2} \mathrm{O}<\mathrm{K}_{6}[\mathbf{1}]$. $n \mathrm{H}_{2} \mathrm{O}$.

The temperature dependence of the ionic conductivities was also examined for the single-crystal samples in the temperature range of $100-340 \mathrm{~K}$ (Fig. 3a). For $\mathrm{Li}_{6}[\mathbf{1}] \cdot n \mathrm{H}_{2} \mathrm{O}$, the conductivity increased almost linearly from $7.0 \times 10^{-10} \mathrm{~S} \mathrm{~cm}^{-1}$ at $240 \mathrm{~K}$ to $1.9 \times 10^{-5} \mathrm{~S} \mathrm{~cm}^{-1}$ at $340 \mathrm{~K}$. The conductivity of $\mathrm{K}_{6}[1] \cdot n \mathrm{H}_{2} \mathrm{O}$ also increased almost linearly from $3.8 \times 10^{-8} \mathrm{~S} \mathrm{~cm}^{-1}$ at $190 \mathrm{~K}$ to 3.0 $\times 10^{-3} \mathrm{~S} \mathrm{~cm}^{-1}$ at $260 \mathrm{~K}$, but a reduced slope was observed at higher temperatures, reaching a conductivity of $1.7 \times$ $10^{-2} \mathrm{~S} \mathrm{~cm}^{-1}$ at $340 \mathrm{~K}$; similar behavior was found for $\mathrm{Na}_{6}[\mathbf{1}]$. $n \mathrm{H}_{2} \mathrm{O}$. If the conductivity obeys the Arrhenius model, the Arrhenius plot ( $\ln \sigma T$ vs. $1 / T$ ) should be linear. By fitting the linear regions based on the Arrhenius equation, the activation energies $\left(E_{\mathrm{a}}\right)$ of conduction for $\mathrm{Li}_{6}[\mathbf{1}] \cdot n \mathrm{H}_{2} \mathrm{O}, \mathrm{Na}_{6}[\mathbf{1}] \cdot n \mathrm{H}_{2} \mathrm{O}$ and
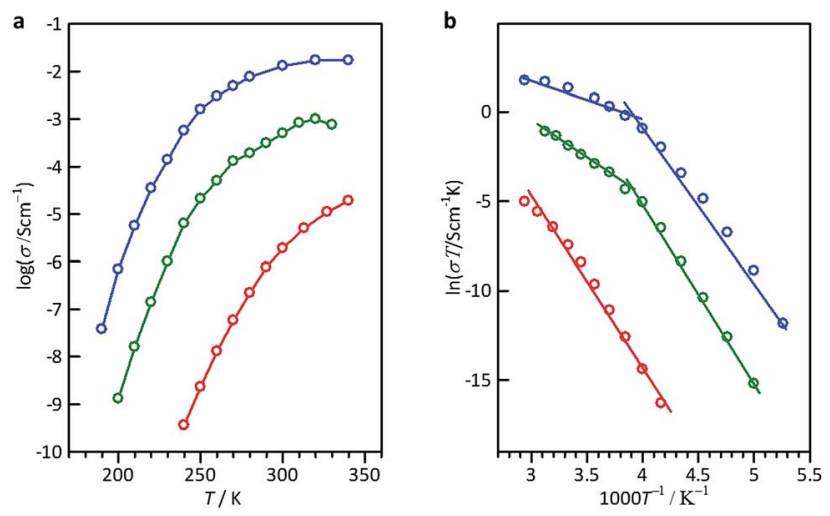

Fig. 3 Conductivity data of single-crystals of $\mathrm{M}_{6}[1] \cdot n \mathrm{H}_{2} \mathrm{O}$. (a) Temperature-dependent ionic conductivities $(\sigma)$ of single-crystals of $\mathrm{K}_{6}[1] \cdot n \mathrm{H}_{2} \mathrm{O}$ (blue), $\mathrm{Na}_{6}[1] \cdot n \mathrm{H}_{2} \mathrm{O}$ (green), and $\mathrm{Li}_{6}[1] \cdot n \mathrm{H}_{2} \mathrm{O}$ (red). (b) Arrhenius plots of $\mathrm{K}_{6}[1] \cdot n \mathrm{H}_{2} \mathrm{O}$ (blue), $\mathrm{Na}_{6}[1] \cdot n \mathrm{H}_{2} \mathrm{O}$ (green), and $\mathrm{Li}_{6}[1]$. $n \mathrm{H}_{2} \mathrm{O}$ (red).
$\mathrm{K}_{6}[\mathbf{1}] \cdot n \mathrm{H}_{2} \mathrm{O}$ were evaluated to be $77 \mathrm{~kJ} \mathrm{~mol}^{-1}(0.80 \mathrm{eV})$, $78 \mathrm{~kJ} \mathrm{~mol}^{-1}(0.81 \mathrm{eV})$ and $68 \mathrm{~kJ} \mathrm{~mol}^{-1}(0.70 \mathrm{eV})$, respectively (Fig. 3b). These $E_{\mathrm{a}}$ values are much higher than those of aqueous alkali halides $\left(E_{\mathrm{a}}=0.1-0.2 \mathrm{eV}\right)^{13}$ and of well-known superionic conductors, such as NASICON and $\operatorname{KSICON}\left(E_{\mathrm{a}}=\right.$ 0.05-0.3 eV). ${ }^{14}$ However, $E_{\mathrm{a}}$ for $\mathrm{K}_{6}[\mathbf{1}] \cdot n \mathrm{H}_{2} \mathrm{O}$ in the highconductivity region $(270-340 \quad \mathrm{~K})$ was evaluated to be $16 \mathrm{~kJ} \mathrm{~mol}^{-1}(0.17 \mathrm{eV})$, which is more consistent with values for superionic conductors. Considering the conductivity value of $0.013 \mathrm{~S} \mathrm{~cm}^{-1}$ at $300 \mathrm{~K}$ and the activation energy of $0.17 \mathrm{eV}$ at approximately the same temperature, single crystals of $K_{6}[\mathbf{1}]$. $n \mathrm{H}_{2} \mathrm{O}$ fulfill the requirements for fast ionic conductors $\left(\sigma_{300 \mathrm{~K}}>\right.$ $\left.10^{-3} \mathrm{~S} \mathrm{~cm}^{-1}\right)$ and approach the values required for 'advanced superionic conductors' $\left(\sigma_{300 \mathrm{~K}}>0.1 \mathrm{~S} \mathrm{~cm}^{-1}, E_{\mathrm{a}} \sim 0.1 \mathrm{eV}\right){ }^{15}$

Despite having the same number of carrier ions and similar conducting pathways, $\mathrm{Li}_{6}[\mathbf{1}] \cdot n \mathrm{H}_{2} \mathrm{O}, \mathrm{Na}_{6}[\mathbf{1}] \cdot n \mathrm{H}_{2} \mathrm{O}$ and $\mathrm{K}_{6}[\mathbf{1}]$. $n \mathrm{H}_{2} \mathrm{O}$ have AC conductivities that depend strongly on the alkali metal ions in $\mathrm{M}_{6}[\mathbf{1}] \cdot n \mathrm{H}_{2} \mathrm{O}$ in the order of $\mathrm{Li}_{6}[\mathbf{1}] \cdot n \mathrm{H}_{2} \mathrm{O}<\mathrm{Na}_{6}[\mathbf{1}]$. $n \mathrm{H}_{2} \mathrm{O}<\mathrm{K}_{6}[\mathbf{1}] \cdot n \mathrm{H}_{2} \mathrm{O}$. This is remarkable because, based on the naked ionic radii of the alkali metal ions, $\mathrm{K}_{6}[\mathbf{1}] \cdot n \mathrm{H}_{2} \mathrm{O}$ would be expected to have the lowest conductivity: $\mathrm{Li}^{+}$(radius of $90 \mathrm{pm}$ ) < $\mathrm{Na}^{+}(116 \mathrm{pm})<\mathrm{K}^{+}(152 \mathrm{pm}) .{ }^{15}$ In aqueous solutions, the charge carriers are hydrated ions $\left[\mathrm{M}\left(\mathrm{H}_{2} \mathrm{O}\right)_{n}\right]^{+}$, so the conductivity order is governed by the order of the hydration radii, $\mathrm{Li}^{+}(340 \mathrm{pm})>$ $\mathrm{Na}^{+}(276 \mathrm{pm})>\mathrm{K}^{+}(232 \mathrm{pm})$, which is opposite to that of the naked ionic radii. ${ }^{16}$ In our system, it is reasonable to consider that the carrier ions have hydrated forms different from those in aqueous solution because the narrowest section of the conducting pathway in $\mathrm{M}_{6}[\mathbf{1}] \cdot n \mathrm{H}_{2} \mathrm{O}$ is approximately $500 \mathrm{pm}$ in diameter, which is smaller than or comparable with twice the hydration radii of the alkali metal ions $\left(464\left(\mathrm{~K}^{+}\right)-680 \mathrm{pm}\left(\mathrm{Li}^{+}\right)\right)$. We speculate that aqua ligands bound to alkali metal ions are, at least in part, exchanged by carboxylate groups of $[1]^{6-}$ during the ion-transport process, as those in biological potassium channels (Fig. 4). ${ }^{17}$ The higher rate of water ligand exchange undergone by heavier alkali metal ions ${ }^{\mathbf{1 8}}$ should lead to more facile movement of carrier ions in $\mathrm{K}_{6}[\mathbf{1}] \cdot n \mathrm{H}_{2} \mathrm{O}$ than in $\mathrm{Na}_{6}[\mathbf{1}]$. $n \mathrm{H}_{2} \mathrm{O}$ and $\mathrm{Li}_{6}[\mathbf{1}] \cdot n \mathrm{H}_{2} \mathrm{O}$. The conduction of alkali metal ions in the solid state has been recognized in glasses, ${ }^{19}$ polymers, ${ }^{20}$ ceramics, ${ }^{21}$ and metal-organic complexes. ${ }^{22,23}$ However, superionic conduction of $\mathrm{K}^{+}$ions has only been achieved in ceramics, which are naked $\mathrm{K}^{+}$ion conductors. ${ }^{21}$ The AC conductivity value

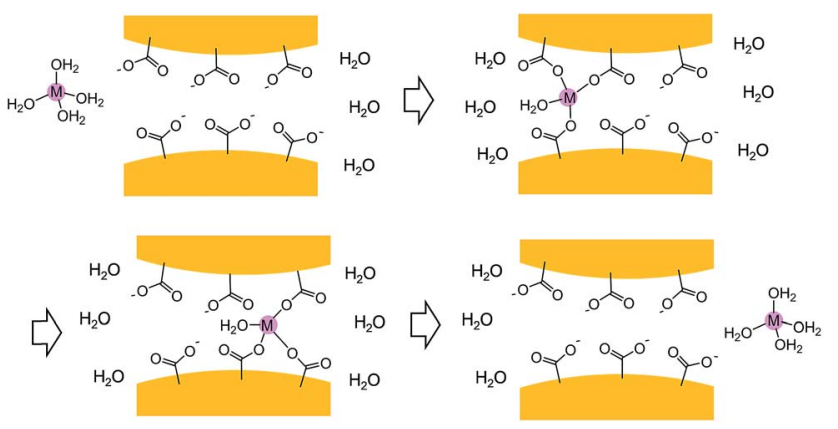

Fig. 4 A schematic illustration of conducting mechanism of hydrated alkali metal ion through the narrowest section in the hydrogen bonded framework of $[1]^{6-}$ 
for a single crystal of $\mathrm{K}_{6}[\mathbf{1}] \cdot n \mathrm{H}_{2} \mathrm{O}$ reached the superionic level of $1.3 \times 10^{-2} \mathrm{~S} \mathrm{~cm}^{-1}$ at room temperature $(300 \mathrm{~K})$ - the highest conductivity yet described for hydrated $\mathrm{K}^{+}$ions in the solid state. In terms of processability, solid $\mathrm{K}_{6}[\mathbf{1}] \cdot n \mathrm{H}_{2} \mathrm{O}$ has important advantages over ceramic conductors since the latter commonly require thermal annealing for preparation and can neither be recrystallized nor converted to other forms.

\section{Solid-state NMR spectroscopy}

Solid-state NMR techniques have often been applied to study the conductivity behavior of alkali metal ions. ${ }^{24}$ In the static solid-state ${ }^{7} \mathrm{Li}$ NMR spectrum at room temperature, $\mathrm{Li}_{6}[\mathbf{1}] \cdot n \mathrm{H}_{2} \mathrm{O}$ gave rise to a singlet signal at $1.0 \mathrm{ppm}$ with a full width at half maximum (FWHM) of $920 \mathrm{~Hz}$ (Fig. 5a). When magic-angle spinning (MAS) was applied at $6 \mathrm{kHz}$, the signal narrowed to a FWHM value of $238 \mathrm{~Hz}$ (Fig. 5b), indicating a large first-order quadrupole interaction of the ${ }^{7} \mathrm{Li}$ nuclei. ${ }^{24}$ The ${ }^{7} \mathrm{Li}$ signal became even sharper with a FWHM value of $133 \mathrm{~Hz}$ when ${ }^{1} \mathrm{H}$ decoupling and MAS were applied simultaneously (Fig. 5c), demonstrating coupling between the lithium and hydrogen nuclei from coordinated water molecules. The appearance of a sharp singlet signal means that the higher-order quadrupole effect around a lithium center is averaged, just as in solution. Thus, it appears that the hydrated $\mathrm{Li}^{+}$ions in the crystal lattice of $\mathrm{Li}_{6}[\mathbf{1}] \cdot n \mathrm{H}_{2} \mathrm{O}$ are mobile on the NMR timescale. This is in sharp contrast to inorganic Li-conducting crystals, such as LISICON $\left(\mathrm{Li}_{3.28} \mathrm{Ga}_{0.24} \mathrm{GeO}_{4}\right)$, which commonly show anisotropic ${ }^{7} \mathrm{Li}$ patterns with side bands in superionic conduction phases. ${ }^{25}$ Because the side bands reflect the presence of $\mathrm{Li}^{+}$ions at lowsymmetry sites, a site-hopping mechanism has been proposed for $\mathrm{Li}^{+}$conduction in the LISICON system. ${ }^{25}$ In the present system, the infinite channels in the lattice allow hydrated $\mathrm{Li}^{+}$ ions to migrate smoothly through the crystal. We also measured

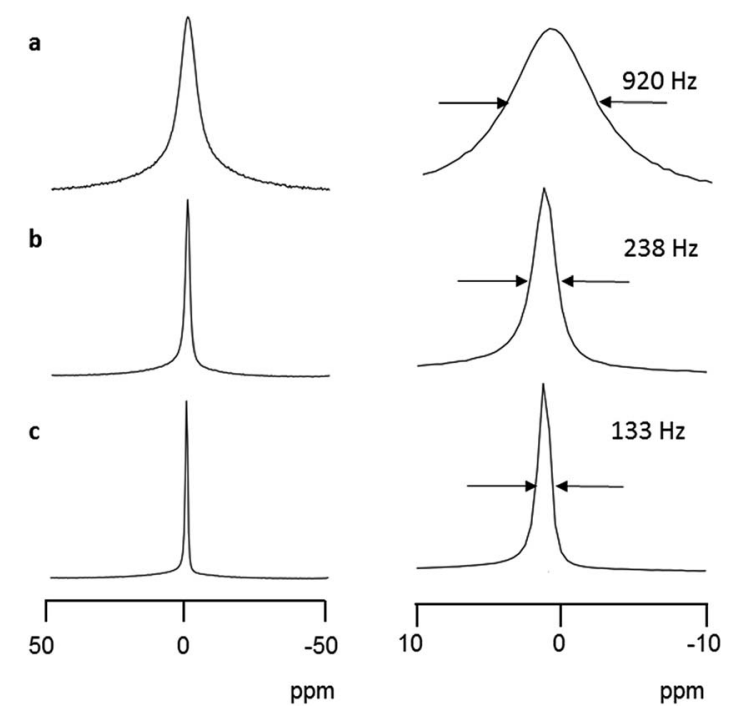

Fig. $5{ }^{7} \mathrm{Li}$ NMR spectra in the solid state. The measured spectra (left) were magnified in the horizontal axis (right). (a) Static (without MAS) at $298 \mathrm{~K}$, (b) MAS $(6 \mathrm{kHz})$ at $298 \mathrm{~K}$, and (c) MAS $(6 \mathrm{kHz})$ with ${ }^{1} \mathrm{H}$-decoupling at $298 \mathrm{~K}$. The arrows indicate the half-maximum widths of the signals. static solid-state ${ }^{23} \mathrm{Na}$ and ${ }^{39} \mathrm{~K}$ NMR spectra at room temperature for $\mathrm{Na}_{6}[\mathbf{1}] \cdot n \mathrm{H}_{2} \mathrm{O}$ and $\mathrm{K}_{6}[\mathbf{1}] \cdot n \mathrm{H}_{2} \mathrm{O}$, respectively. Again, a sharp singlet signal was observed in each spectrum $\left(-11.2\right.$ ppm with a FWHM of $1299 \mathrm{~Hz}$ for $\mathrm{Na}_{6}[\mathbf{1}] \cdot n \mathrm{H}_{2} \mathrm{O}$ and $-0.7 \mathrm{ppm}$ with a FWHM of $455 \mathrm{~Hz}$ for $\mathrm{K}_{6}[1] \cdot n \mathrm{H}_{2} \mathrm{O}$ ), supporting the mobility of hydrated $\mathrm{Na}^{+}$and $\mathrm{K}^{+}$ions in $\mathrm{M}_{6}[\mathbf{1}] \cdot n \mathrm{H}_{2} \mathrm{O}$, as in the case of hydrated $\mathrm{Li}^{+}$ions (Fig. $\mathrm{S} 15$ and $\mathrm{S} 16 \dagger$ ).

For $\mathrm{Li}_{6}[\mathbf{1}] \cdot n \mathrm{H}_{2} \mathrm{O}$ and $\mathrm{Na}_{6}[\mathbf{1}] \cdot n \mathrm{H}_{2} \mathrm{O}$, the ${ }^{7} \mathrm{Li}$ and ${ }^{23} \mathrm{Na}$ spinlattice relaxation rates $\left(T_{1}\right)$ were analyzed by the Bloembergen-Purcell-Pound (BPP) equation, ${ }^{26}$ the Arrhenius equation, and an ion-diffusion model (Fig. S17 and S18 $\dagger$ ). These analyses gave the diffusion constant $D$ of $1.2 \times 10^{-8} \mathrm{~cm}^{2} \mathrm{~s}^{-1}$ for $\mathrm{Li}^{+}$and $7.2 \times 10^{-8} \mathrm{~cm}^{2} \mathrm{~s}^{-1}$ for $\mathrm{Na}^{+}$. Conductivities of $1.3 \times 10^{-4} \mathrm{~S} \mathrm{~cm}^{-1}$ for $\mathrm{Li}_{6}[\mathbf{1}] \cdot n \mathrm{H}_{2} \mathrm{O}$ and $8.4 \times 10^{-4} \mathrm{~S} \mathrm{~cm}^{-1}$ for $\mathrm{Na}_{6}[\mathbf{1}] \cdot n \mathrm{H}_{2} \mathrm{O}$ were also obtained from these analyses, which are consistent with the conductivity order of $\mathrm{Li}_{6}[\mathbf{1}] \cdot n \mathrm{H}_{2} \mathrm{O}<\mathrm{Na}_{6}[\mathbf{1}] \cdot n \mathrm{H}_{2} \mathrm{O}$ from the AC impedance method. Unfortunately, $T_{1}$ for the ${ }^{39} \mathrm{~K}$ nuclei could not be evaluated due to very fast relaxation at room temperature; measurements at lower temperature were not obtained owing to instrument limitations.

\section{Ion diffusion in the solid state}

The AC impedances and the solid-state NMR spectra of $\mathbf{M}_{6}[\mathbf{1}]$. $n \mathrm{H}_{2} \mathrm{O}$ might be explained by long-range cation transportation through the crystal lattice or by more localized cation oscillations within the lattice pores. If the carrier ions are transported through a crystal lattice, they should be readily exchanged by exogenous ions. To check this, the mutual diffusion of $\mathrm{Na}^{+}$and $\mathrm{K}^{+}$ions in the solid state was investigated. We prepared a heteroconjugated pellet (1.5 $\mathrm{mm}$ diameter, $5.0 \mathrm{~mm}$ thickness) in which cylindrical-shaped pellets of $\mathrm{Na}_{6}[\mathbf{1}] \cdot n \mathrm{H}_{2} \mathrm{O}$ and $\mathrm{K}_{6}[\mathbf{1}]$. $n \mathrm{H}_{2} \mathrm{O}$ with the same size were bonded together (Fig. S19†), followed by allowing resulting structure to stand at room temperature for $100 \mathrm{~h}$. The atomic absorption and X-ray fluorescence analyses revealed that $\mathrm{Na}^{+}$and $\mathrm{K}^{+}$ions exist at almost equal amounts on both sides of the pellet, indicative of the migration of $\mathrm{Na}^{+}$and $\mathrm{K}^{+}$ions over the heteroconjugated pellet. Based on Fick's law of $\chi^{2}=2 D t$, where $\chi, D$, and $t$ represent the diffusion distance, diffusion constant, and diffusion time, respectively,,$^{27,28}$ the $D$ value was evaluated to be $8.7 \times 10^{-8} \mathrm{~cm}^{2}$ $\mathrm{s}^{-1}$, given that $\chi$ is $2.5 \mathrm{~mm}$ after $100 \mathrm{~h}$. This is comparable with the $D$ value evaluated from the $T_{1}$ analysis of the ${ }^{23} \mathrm{Na}$ nucleus of $\mathrm{Na}_{6}[\mathbf{1}] \cdot n \mathrm{H}_{2} \mathrm{O}\left(D=7.2 \times 10^{-8} \mathrm{~cm}^{2} \mathrm{~s}^{-1}\right.$ at $\left.300 \mathrm{~K}\right)$.

\section{Ion exchange reactions}

The cation transportation through the crystal lattice in $\mathbf{M}_{6}[\mathbf{1}]$. $n \mathrm{H}_{2} \mathrm{O}$ was also verified by the ion exchange reactions using single crystals of $\mathrm{K}_{6}[\mathbf{1}] \cdot n \mathrm{H}_{2} \mathrm{O}$ that were soaked in a sodium acetate solution at room temperature. The atomic absorption and X-ray fluorescence analyses, together with the ${ }^{23} \mathrm{Na}$ NMR spectral measurements, revealed that the $\mathrm{K}^{+}$-to- $\mathrm{Na}^{+}$ion exchange to yield $\mathrm{Na}_{6}[\mathbf{1}] \cdot n \mathrm{H}_{2} \mathrm{O}$ was almost completed within 5 min (Fig. 6). Similarly, $\mathrm{K}_{6}[1] \cdot n \mathrm{H}_{2} \mathrm{O}$ was quickly converted to $\mathrm{Li}_{6}[\mathbf{1}] \cdot n \mathrm{H}_{2} \mathrm{O}$ by soaking single crystals of $\mathrm{K}_{6}[\mathbf{1}] \cdot n \mathrm{H}_{2} \mathrm{O}$ in a solution of lithium acetate, which was confirmed by ${ }^{7} \mathrm{Li}$ NMR and the other techniques mentioned above (Fig. 6). These solid-state 
(a)
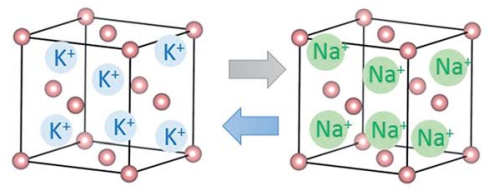

(b)

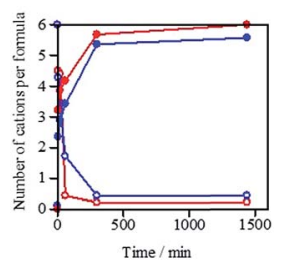

Fig. 6 Cation exchange from $\mathrm{K}_{6}[1] \cdot n \mathrm{H}_{2} \mathrm{O}$ to $\mathrm{M}_{6}[1] \cdot n \mathrm{H}_{2} \mathrm{O}$. (a) Schematic illustration of cation-exchange reactions from $\mathrm{K}_{6}[1] \cdot n \mathrm{H}_{2} \mathrm{O}$ to $\mathrm{Na}_{6}[1] \cdot n \mathrm{H}_{2} \mathrm{O}$ and (b) plots of number of cations per formula vs. time. The number of cations per formula was determined based on the atomic absorption experiment. Two experiments, (i) the conversion from $\mathrm{K}_{6}[1] \cdot n \mathrm{H}_{2} \mathrm{O}$ to $\mathrm{Na}_{6}[1] \cdot n \mathrm{H}_{2} \mathrm{O}$ by soaking crystals of $\mathrm{K}_{6}[1] \cdot n \mathrm{H}_{2} \mathrm{O}$ in a $0.1 \mathrm{M} \mathrm{NaOAc}$ solution in a water/ethanol mixture (red open and filled circles represent the amount of $\mathrm{Na}^{+}$and $\mathrm{K}^{+}$, respectively), and (ii) the conversion from $\mathrm{K}_{6}[1] \cdot n \mathrm{H}_{2} \mathrm{O}$ to $\mathrm{Li}_{6}[1] \cdot n \mathrm{H}_{2} \mathrm{O}$ by soaking crystals of $\mathrm{K}_{6}[1] \cdot n \mathrm{H}_{2} \mathrm{O}$ in a $0.1 \mathrm{M} \mathrm{LiOAc}$ solution in a water/ethanol mixture (blue open and filled circles represent the amount of $\mathrm{Li}^{+}$and $\mathrm{K}^{+}$, respectively), were performed. The sample was analyzed after $5 \mathrm{~min}, 20 \mathrm{~min}$, $60 \mathrm{~min}, 300 \mathrm{~min}$, and $1440 \mathrm{~min}$.

cation-exchange reactions strongly support that the alkali metal ions in $\mathrm{M}_{6}[\mathbf{1}] \cdot n \mathrm{H}_{2} \mathrm{O}$ are transported through the crystal lattice to induce ion-conducting properties. Cation exchange proceeds with retention of single crystallinity, since the structures of the product crystals were subsequently determined by single-crystal $\mathrm{X}$-ray analysis.

\section{Experimental}

\section{Materials}

All chemicals were of commercial grade and used without further purification.

\section{Preparation of $K_{6}[1] \cdot n \mathrm{H}_{2} \mathrm{O}$}

This compound was prepared according to a literature procedure. ${ }^{10}$ To a suspension containing $\Delta_{\mathrm{LLL}}-\left[\mathrm{Rh}(\mathrm{L}-\mathrm{Hcys})_{3}\right](200 \mathrm{mg}$, $0.43 \mathrm{mmol})$ in water $(10 \mathrm{~mL})$, excess amounts of $\mathrm{ZnO}(369 \mathrm{mg}$, $4.54 \mathrm{mmol}$ ) and $\mathrm{ZnBr}_{2}$ (212 $\mathrm{mg}, 0.94 \mathrm{mmol}$ ) were added. The $\mathrm{pH}$ of the mixture was adjusted to $c a$. 9 using an aqueous solution of $\mathrm{KOH}$. After insoluble $\mathrm{ZnO}$ was removed by filtration, the yellow filtrate was concentrated to a small volume with a rotary evaporator. Yellow block crystals of $\mathrm{K}_{6}[1] \cdot n \mathrm{H}_{2} \mathrm{O}$ suitable for Xray diffraction analysis were obtained by storing the solution in a refrigerator. Yield: $204 \mathrm{mg}$ (59\%).

\section{Preparation of $\mathrm{H}_{6}[1] \cdot 15 \mathrm{H}_{2} \mathrm{O}$}

An aqueous solution of $\mathrm{HNO}_{3}(0.5 \mathrm{M})$ was added dropwise to an aqueous solution of $\mathrm{K}_{6}[\mathbf{1}] \cdot n \mathrm{H}_{2} \mathrm{O}(50 \mathrm{mg}, 16 \mu \mathrm{mol})$, and a paleyellow solid precipitated immediately. After allowing it to stand at room temperature overnight, the resulting pale-yellow powder was collected by filtration and washed with water. Yield: $33 \mathrm{mg}(88 \%)$.

\section{Preparation of $\mathrm{Li}_{6}[1] \cdot n \mathrm{H}_{2} \mathrm{O}$ and $\mathrm{Na}_{6}[1] \cdot n \mathrm{H}_{2} \mathrm{O}$}

An aqueous solution of $\mathrm{LiOH}(0.1 \mathrm{M}, 0.70 \mathrm{~mL}, 70 \mu \mathrm{mol})$ and an aqueous solution of $\mathrm{LiCl}(19 \mathrm{M}, 1.0 \mathrm{~mL}, 19 \mathrm{mmol})$ were added to a suspension of $\mathrm{H}_{6}[\mathbf{1}] \cdot 15 \mathrm{H}_{2} \mathrm{O}(30 \mathrm{mg}, 10 \mu \mathrm{mol})$ in water $(5 \mathrm{~mL})$. The slow diffusion of EtOH into the resulting yellow solution gave yellow block crystals suitable for X-ray diffraction analysis, which were collected by filtration. Yield: $23 \mathrm{mg}$ (62\%). A similar reaction using $\mathrm{NaOH} / \mathrm{NaCl}$ instead of $\mathrm{LiOH} / \mathrm{LiCl}$ gave $\mathrm{Na}_{6}[\mathbf{1}]$. $n \mathrm{H}_{2} \mathrm{O}$ as yellow block crystals suitable for X-ray diffraction analysis. Yield: $22 \mathrm{mg}$ (55\%).

The concentration of $\mathrm{Li}^{+}$or $\mathrm{Na}^{+}$ions in each sample was evaluated from its ${ }^{7} \mathrm{Li}$ or ${ }^{23} \mathrm{Na} \mathrm{NMR}$ spectrum in $\mathrm{D}_{2} \mathrm{O}$, with fitting its signal intensity to the calibration line of $\mathrm{Li}^{+}$or $\mathrm{Na}^{+}$ concentrations versus ${ }^{7} \mathrm{Li}$ or ${ }^{23} \mathrm{Na}$ signal intensities. The calibration lines were made by measuring the ${ }^{7} \mathrm{Li}$ or ${ }^{23} \mathrm{Na} \mathrm{NMR}$ spectra for four standard $\mathrm{D}_{2} \mathrm{O}$ solutions of $\mathrm{LiCl}$ or $\mathrm{NaCl}$ with different concentrations. The experiments showed that each sample contains $6 \mathrm{Li}^{+}$or $\mathrm{Na}^{+}$ions per formula unit due to the complete cation-exchange reactions.

\section{Ion diffusion experiments}

A cylindrical pellet of $\mathrm{K}_{6}[\mathbf{1}] \cdot n \mathrm{H}_{2} \mathrm{O}(1.5 \mathrm{~mm}$ diameter, $1.5 \mathrm{~mm}$ thickness) was prepared by pressing a crystalline sample of $\mathrm{K}_{6}[\mathbf{1}] \cdot n \mathrm{H}_{2} \mathrm{O}$ in a pellet die. On the pellet of $\mathrm{K}_{6}[\mathbf{1}] \cdot n \mathrm{H}_{2} \mathrm{O}$, a crystalline sample of $\mathrm{Na}_{6}[\mathbf{1}] \cdot n \mathrm{H}_{2} \mathrm{O}$ was added in the pellet die, followed by pressing them to give a hetero-conjugated pellet of $\mathrm{Na}_{6}[\mathbf{1}] \cdot n \mathrm{H}_{2} \mathrm{O}-\mathrm{K}_{6}[\mathbf{1}] \cdot n \mathrm{H}_{2} \mathrm{O}(1.5 \mathrm{~mm}$ diameter, $3.0 \mathrm{~mm}$ thickness). The hetero-conjugated pellet was allowed to stand at room temperature for $100 \mathrm{~h}$, and then the pellet was round sliced into four parts. The amount of $\mathrm{K}^{+}$ions in each part of the pellet was estimated by the atomic absorption and X-ray fluorescence analyses.

\section{Cation exchange experiments}

Freshly prepared yellow crystals of $\mathrm{K}_{6}[\mathbf{1}] \cdot n \mathrm{H}_{2} \mathrm{O}$ were soaked in a solution of sodium acetate or lithium acetate $(0.1 \mathrm{M})$ in $\mathrm{H}_{2} \mathrm{O}$ / EtOH $(1: 3 \mathrm{v} / \mathrm{v})$ at room temperature for 1 day. During this period of time, the crystals remained shiny without changing their crystalline morphology. After the cation-exchange experiment, one of the crystals was selected for single-crystal X-ray diffraction analysis. During the cation-exchange experiments, the amounts of cationic species in the crystals were monitored using the atomic absorption spectroscopy, as well as the ${ }^{23} \mathrm{Na} /{ }^{7} \mathrm{Li} \mathrm{NMR}$ and X-ray fluorescence measurements.

\section{Physical measurements}

IR spectra were recorded on a JASCO (Tokyo, Japan) FT/IR-4700 infrared spectrophotometer at room temperature. Elemental analysis (C, H, N) was performed at Osaka University using a YANACO (Kyoto, Japan) CHN Corder MT-5 or MT-6. The ${ }^{1} \mathrm{H}$, ${ }^{7} \mathrm{Li}$, and ${ }^{23} \mathrm{Na} N \mathrm{NMR}$ spectra were measured in $\mathrm{D}_{2} \mathrm{O}$ using a JEOL (Tokyo, Japan) EX-500 spectrometer at the probe temperature using sodium 4,4'-dimethyl-4-silapentane-1-sulfonate (DSS) ( $\delta$ $=0.0 \mathrm{ppm}$ ) as an internal standard for ${ }^{1} \mathrm{H}$ NMR measurements and lithium chloride and sodium chloride $(\delta=0.0 \mathrm{ppm})$ as external standards for the ${ }^{7} \mathrm{Li}$ and ${ }^{23} \mathrm{Na}$ NMR measurements, respectively. The solid-state ${ }^{1} \mathrm{H},{ }^{7} \mathrm{Li}$, and ${ }^{23} \mathrm{Na}$ NMR spectra were measured using a Chemagnetics (Tokyo, Japan) CMX300 spectrometer at the probe temperature using adamantane $(\delta=1.91$ 
ppm), $\mathrm{LiCl}(\delta=0.00 \mathrm{ppm})$, or $\mathrm{NaCl}(\delta=7.21 \mathrm{ppm})$ as external standards. The solid-state ${ }^{39} \mathrm{~K}$ NMR spectra were measured using a Bruker AVANCEIII600WB spectrometer at the probe temperature using $\mathrm{KCl}(\delta=47.8 \mathrm{ppm})$ as the external standard. Details of the NMR data analysis are described in ESI. $\dagger$ Atomic absorption analysis was performed using a Shimadzu (Kyoto, Japan) AA-6200 Atomic Absorption Spectrophotometer. Thermogravimetric and differential thermal analysis (TG/DTA) measurements were carried out using a Shimadzu (Kyoto, Japan) DTG-60.

\section{Alternating current conductivity analysis}

The AC conductivity measurements for single-crystal samples were carried out on a Solartron (West Sussex, United Kingdom) SI 1260 impedance/gain-phase analyzer and a Solartron dielectric interface 1296 using a two-probe method. The sample was attached to the measurement insert probe for variable temperature analysis with a cryogen-free cryostat, and the AC impedance was measured under controlled temperature from 150 to $350 \mathrm{~K}$. During the temperature-controlled experiment, the atmosphere around the coated sample was replaced by He gas. The data were collected from $3 \mathrm{MHz}$ to $0.1 \mathrm{~Hz}$. Details of the measurements and data analysis are described in ESI. $\dagger$

\section{X-ray diffraction analysis}

Single-crystal XRD data for $\mathrm{Li}_{6}[\mathbf{1}] \cdot n \mathrm{H}_{2} \mathrm{O}$ and $\mathrm{Na}_{6}[\mathbf{1}] \cdot n \mathrm{H}_{2} \mathrm{O}$ were recorded on a Rigaku (Tokyo, Japan) Mercury 2 CCD detector with synchrotron radiation at the BL02B1 beamline at SPring-8 with the approval of the Japan Synchrotron Radiation Research Institute (JASRI). The intensity data were collected by the $\omega$-scan technique and were processed with the Rapid Auto software program supplied by Rigaku (Tokyo, Japan). Single-crystal XRD data for $\mathrm{K}_{6}[\mathbf{1}] \cdot n \mathrm{H}_{2} \mathrm{O}$ were recorded at $100 \mathrm{~K}$ with an ADSC Q210 CCD area detector with synchrotron radiation at the $2 \mathrm{D}$ beamline at the Pohang Accelerator Laboratory (PAL). Details of the structural analysis are described in ESI. $\dagger$

Powder XRD (PXRD) patterns were recorded in transmission mode at the BL02B2 beamline at SPring-8 under controlled temperature with the approval of JASRI. The finely ground crystals were placed in $0.3 \mathrm{~mm}$ glass capillary tubes. The powder simulation patterns were generated from the single-crystal X-ray structures using Mercury 3.0.

\section{Conclusions}

It is a general concept that cationic and anionic species in ionic crystals rarely migrate because they are tightly fixed in crystal lattices due to coulombic interactions. The present work reported a unique example of an ionic crystal that shows an ultrahigh mobility of hydrated potassium ions in the solid state similar to that in the solution state. The high mobility leads to superionic conductivity in the crystal, as well as the rapid exchange by other alkali metal ions. The dominant contribution of hydrated alkali metal ions as a conducting species was further evidenced by multinuclear NMR and ion-diffusion experiments for the heteroconjugated pellets. The compounds we describe here have important advantages over ceramic conductors in terms of processability. Our findings will contribute not only to the deep understanding of the ionmigration phenomena in the solid state but also to innovative advances towards practical applications of ion-conducting solid materials, such as batteries and sensors.

\section{Conflicts of interest}

There are no conflicts to declare.

\section{Acknowledgements}

This work was supported in part by CREST, JST (Grant No. JPMJCR13L3) and JSPS KAKENHI (Grant No. 16K13609), as well as the Tokuyama Science Foundation. The synchrotron radiation experiments were performed at BL02B1 and BL02B2 of SPring-8 with the approval of JASRI (Proposal No. 2015B1237, 2015B1241, 2016A1073). We thank Mr Ukyo Yamashita for experimental assistance; Prof. Takahiro Ueda, Dr Yasuto Todokoro, and Dr Hitoshi Haneoka (Osaka University, Japan) for measurements and discussions regarding the solid-state NMR experiments; and Prof. Malcolm Halcrow (University of Leeds, United Kingdom) for helpful discussions.

\section{Notes and references}

1 P. Atkins and D. P. Julio, Elements of physical chemistry, Oxford University Press, 2013.

2 C. Tubandt and E. Lorenz, Z. Phys. Chem., 1914, 87, 513-543.

3 P. H. L. Notten, F. Roozeboom, R. A. H. Niessen and L. Baggetto, Adv. Mater., 2007, 19, 4564-4567.

4 B. C. H. Steele and A. Heinzel, Nature, 2001, 414, 345-352.

5 R. Ramamoorthy, P. K. Dutta and S. A. Akbar, J. Mater. Sci., 2003, 38, 4271-4282.

6 C. Wagner, Prog. Solid State Chem., 1972, 7, 1-37.

7 J. B. Goodenough and K.-S. Park, J. Am. Chem. Soc., 2013, 135, 1167-1176.

8 D. Larcher and J.-M. Tarascon, Nat. Chem., 2015, 7, 19-29.

9 G. Greeuw and J. F. Verwey, J. Appl. Phys., 1984, 56, 22182224.

10 T. Konno, K. Okamoto and J. Hidaka, Inorg. Chem., 1994, 33, 538-544.

11 N. Yoshinari, U. Yamashita and T. Konno, CrystEngComm, 2013, 15, 10016-10019.

12 Before the measurements that were carried out under vacuum conditions, each single-crystal sample was quickly covered with an insulating glue to prevent crystal dehydration. A single-crystal without glue-coating showed a much lower conductivity $\left(5.9 \times 10^{-6} \mathrm{~S} \mathrm{~cm}^{-1}\right.$ at $300 \mathrm{~K}$ for $\left.\mathrm{K}_{6}[\mathbf{1}] \cdot n \mathrm{H}_{2} \mathrm{O}\right)$ due to dehydration.

13 T. Erdey-Gruz, Transport Phenomena in Aqueous Solutions, Akademiai Kiado, Budapest, 1974.

14 F. A. Karamov, Superionic conductors: heterostructures and elements of functional electronics based on them, Cambridge Int Science Publishing, 2008. 
15 A. L. Despotuli, A. V. Andreeva and B. Rambabu, Nanoionics of advanced superionic conductors, portable document format abstract only, Ionics, Springer, Berlin/Heidelberg, vol. 11, 3-4, pp. 306-314, Retrieved 2007-11-02, DOI: 10.1007/BF02430394.

16 J. A. McCleverty and T. J. Meyer, Metal Aqua Ion, in Comprehensive Coordination Chemistry II, Elsevier, 2004, ch. 1.25, pp. 515-551.

17 (a) D. A. Doyle, J. M. Cabral, R. A. Pfuetzner, A. Kuo, J. M. Gulbis, S. L. Cohen, B. T. Chait and R. MacKinnon, Science, 1998, 280, 69-77; (b) J. H. Morais-Cabral, Y. Zhou and R. MacKinnon, Nature, 2001, 414, 37-42.

18 M. Remko, D. Fitz and B. M. Rode, J. Phys. Chem. A, 2008, 112, 7652-7661.

19 A. Pradel and M. Ribes, J. Mater. Sci. Eng. B, 1989, 3, 45-56. 20 Conductive polymers and plastics, ed. J. Margolis, Springer Science \& Business Media, 2012.
21 Superionic conductors, ed. G. Mahan, Springer Science \& Business Media, 2013.

22 F.-S. Ke, Y.-S. Wu and H. Deng, J. Solid State Chem., 2015, 223, 109-121.

23 S. Horike, D. Umeyama and S. Kitagawa, Acc. Chem. Res., 2013, 46, 2376-2384.

24 Solid state NMR spectroscopy: principles and applications, ed. M. J. Duer, John Wiley \& Sons, 2008.

25 R. Bertermann, Z. Naturforsch., 1998, 53, 863.

26 N. Bloembergen, E. M. Purcell and R. V. Pound, Phys. Rev., 1948, 73, 679.

27 A. Fick, Philos. Mag., 1855, 10, 30-39.

28 I. N. Sedyuk, N. R. Zaccai and J. Zaccai, Methods in Molecular Bio-physics: Structure, Dynamics, Function, Cambridge University Press, 2007. 